\title{
Análise dos Homicídios em Pernambuco e as Contribuições da Justiça Restaurativa
}

\author{
Nemésio Dario Vieira de Almeida \\ Universidade Federal de Pernambuco, PE, Brasil
}

\begin{abstract}
Resumo: A violência é compreendida como um conjunto de eventos individuais, sociais, econômicos e culturais, historicamente a acompanhar a humanidade. Ela está associada à intencionalidade, constituindo-se em agravo previsível, e a Psicologia tem importante responsabilidade em sua prevenção. Este estudo analisou a magnitude e a tendência da mortalidade por homicídios ocorridos no estado de Pernambuco, Brasil, no período de 2009 a 2014. Os óbitos por homicídios foram obtidos por meio do Sistema de Informações Policiais da Secretaria de Defesa Social de Pernambuco. Utilizou-se o desenho ecológico exploratório do tipo série temporal. No período, ocorreram 20.891 óbitos por homicídios em Pernambuco; cerca de $56,1 \%$ deles ocorreram no grupo de 15 a 29 anos de idade; houve diferencial no risco de mortalidade segundo sexo e faixa etária. Ainda é difícil de avaliar possíveis resultados e impactos sobre o tema da Justiça Restaurativa, por ser novo e por não ter sido originalmente um modelo criado no cenário brasileiro. As ações específicas devem voltar-se, principalmente, à população de adolescentes e adultos jovens, visto que esses contingentes vêm mantendo os altos níveis de mortalidade por homicídios no estado; destaca-se a necessidade de políticas públicas efetivas para a prevenção à violência.
\end{abstract}

Palavras-chave: Homicídios, Violência, Justiça Restaurativa, Socioeducação.

\section{Analysis of Homicides in Pernambuco and the Contributions of Restorative Justice}

\begin{abstract}
Violence is associated with intentionality, constituting a predictable offense, and psychology has an important responsibility in prevention, being violence understood as a set of individual, social, economic and cultural events that have historically accompanied humanity. This study examined the magnitude and trend of mortality from homicides in the state of Pernambuco, Brazil, from 2009 to 2014. Deaths by homicide were obtained from the System Information Officers of the Social Defense Secretariat of Pernambuco. We used the exploratory ecological model of the time series type. In the period, there were 20,891 deaths from homicides in Pernambuco; about $56.1 \%$ of them occurred in the group 15-29 years of age; there was difference in the risk of mortality by sex and age group. Regarding the theme of restorative justice, being new and not having originally been a model created in the Brazilian scenario, is still difficult to assess possible outcomes and impacts. Specific actions must turn mainly to the population of adolescents and young adults, since these groups have maintained high levels of homicide mortality in the state. The need for effective public policies to prevent violence is highlighted.
\end{abstract}

Keywords: Homicide, Violence, Restorative Justice, Socio-education. 


\title{
Análisis de los Homicidios en Pernambuco y las Contribuciones de la Justicia Restaurativa
}

\begin{abstract}
Resumen: La violencia está asociada con la intencionalidad, que constituye una infracción predecible, y la psicología tiene una responsabilidad importante en la prevención, y la violencia entendida como un conjunto de eventos individuales, sociales, económicos y culturales históricamente acompañan a la humanidad. Este estudio examinó la magnitud y la tendencia de la mortalidad por homicidios en el estado de Pernambuco, Brasil, entre 2009 y 2014. Las muertes por homicidio se obtuvieron de los responsables de información del Sistema de la Secretaría de Defensa Social de Pernambuco. Se utilizó el modelo ecológico exploratorio del tipo de series de tiempo. En el período, hubo 20,891 muertes por homicidios en Pernambuco; cerca de 56,1\% de ellos se produjo en el grupo de 15-29 años de edad; no hubo diferencia en el riesgo de mortalidad por grupos de sexo y edad. En el tema de la justicia restaurativa, al ser nuevo y no haber sido originalmente un modelo creado en el escenario brasileño, todavía es difícil de evaluar los posibles resultados e impactos. Las acciones específicas deben esta relacionadas principalmente a la población de adolescentes y adultos jóvenes, ya que estos grupos han mantenido altos niveles de mortalidad por homicidio en el estado. Se destaca la necesidad de políticas públicas eficaces para prevenir la violencia.
\end{abstract}

Palabras clave: Homicidio, Violencia, Justicia Restaurativa, Socioeducación.

O Meu País. Tô vendo tudo, tô vendo tudo. Mas, fico calado, faz de conta que sou mudo. Um país que crianças eliminam. Que não ouve o clamor dos esquecidos. Onde nunca os humildes são ouvidos. E uma elite sem Deus é quem domina. Que permite um estupro em cada esquina. E a certeza da dúvida infeliz. Onde quem tem razão baixa a cerviz. E massacram-se o negro e a mulher. Pode ser o país de quem quiser/Mas não é, com certeza, o meu país. Um país onde as leis são descartáveis. Por ausência de códigos corretos. Com quarenta milhões de analfabetos. E maior multidão de miseráveis. Um país onde os homens confiáveis. Não têm voz, não tem vez, nem diretriz. Mas corruptos têm voz e vez e bis [...] (Zé Ramalho, 2000).

O poema de Zé Ramalho nos coloca diante do epicentro dos recorrentes espetáculos de violência na atualidade. De acordo com Peres, Ruotti, Carvalho e Regina (2015), desde as últimas décadas do século XX está em desenvolvimento uma modificação na forma de compreender a realidade da violência, segurança e criminalidade e nos estilos de indicar ações para seu enfrentamento. Assim, o enfoque importante dessa fase compreende avanço interdisciplinar: questões que dizem respeito à violência e à segurança estão pouco a pouco deixando de serem objetos particulares da segurança pública e da justiça criminal, sendo agora tratadas como problemas sociais, em um sentido amplo, com repercussão na área da saúde, educação e cultura. Temos também como característica dessa fase, que pode ser considerado um resultado do que foi frisado anteriormente,

[...] a emergência no espaço público de problemas que eram tradicionalmente tratados como questões da esfera privada, a exemplo da violência doméstica e familiar, entre as quais se incluem as situações de violência de gênero ou violência por parceiro íntimo, e de violência contra idosos e crianças (Peres et al., 2015, p. 13).

Para a Organização Mundial da Saúde - OMS (Krug, Dahlberg, Mercy, Zwi, \& Lozano, 2002), a violência está associada à intencionalidade, constituindo-se em agravo previsível, e a Psicologia tem importante responsabilidade em sua prevenção. A violência pode ser compreendida como um conjunto de eventos individuais, sociais, econômicos e culturais, historicamente a acompanhar a humanidade.

A OMS (Krug et al., 2002) entende, também a violência em uma perspectiva ecológica, resultante 
da interação de dimensões (níveis) individuais, relacionais, comunitárias e sociais. O primeiro nível concentra-se na identificação e análise das características da pessoa que aumentam a possibilidade de ser uma vítima ou uma perpetradora. O segundo nível discute a maneira pela qual as relações sociais mais próximas interferem no risco para vitimização e autoria da agressão. O terceiro nível analisa os contextos comunitários em que as relações se inserem (por exemplo, escolas), que contribuem ou não para as situações de conflitos. O último nível analisa os fatores sociais mais amplos que influenciam os índices de violência, como as normas culturais, as políticas de saúde e educacionais.

Já de acordo com Minayo (2005), as expressões de violência têm sido abordadas conforme suas manifestações domésticas ou institucionais. De tal modo, considerados segundo sua natureza, os atos violentos correspondem a quatro modalidades possíveis: física, psicológica, sexual e aquela que envolve qualquer tipo de abandono ou negligência. $\mathrm{O}$ abuso físico denota $\mathrm{o}$ uso da força para produzir danos ou injúrias ao outro, o abuso psicológico envolve agressões verbais ou gestuais, o abuso sexual refere-se à imposição de práticas sexuais por meio de aliciamento ou ameaças e o abandono diz respeito à ausência, recusa ou deserção de cuidados indispensáveis para uma pessoa que dele necessite.

A violência torna-se assim um tema atual de grande interesse, devido ao impacto que provoca na qualidade de vida das pessoas e na necessidade de cuidados prestados pelos serviços psicológicos, médicos e hospitalares. De acordo com a United Nations Office on Drugs and Crime (UNODG), em 2012, quase meio milhão de pessoas morreram por homicídio doloso em todo o mundo, um terço delas (36\%) nas Américas (UNODG, 2013). Naquele mesmo ano, a taxa de mortalidade média no mundo foi de 6,2 homicídios por 100 mil habitantes, e as taxas para os países da América do Sul variaram entre 16 e 23 homicídios por 100 mil habitantes.

Estamos diante de uma epidemia de homicídios no Brasil com taxa de assassinatos de 56 mil mortos por ano, explica Waiselfisz (2014), onde, destes, $30 \mathrm{mil}$ são jovens entre 15 e 29 anos de idade. Entre esses 30 mil, (77\%) são jovens negros e pobres, os quais são as maiores vítimas.

No período de 2000 a 2011, no Brasil, os acidentes e violências representaram a terceira causa de óbito na população geral, atrás apenas dos óbitos causados por doenças cardiovasculares e neoplasias (Nascimento, \& Morais Neto). Esses fenômenos sociais são os que mais têm chamado a atenção dos estudiosos e da sociedade. Segundo a nova edição do levantamento "Mapa da violência 2015: mortes matadas por armas de fogo", de Waiselfisz (2015), ,

42.416 pessoas morreram em 2012 vítimas de arma de fogo no Brasil, o equivalente a 116 óbitos por dia, essa cifra é ainda mais acentuada entre os jovens, que correspondem a cerca de $59 \%$ das estatísticas, o estudo foi realizado pelo governo brasileiro, a Organização das Nações Unidas para a Educação, a Ciência e a Cultura (Unesco) e a Faculdade Latino Americana de Ciências Sociais (Flacso).

De acordo com Waiselfisz (2015), a taxa de mortalidade por armas de fogo no Brasil, indicador que leva em conta o crescimento da população, ficou em 21,9 óbitos para cada 100 mil habitantes, em 2012.Clique para enviar por email a um amigo(abre em nova janela)Clique para compartilhar no LinkedIn(abre em nova janela)

Essa taxa é a segunda mais alta já registrada pelo Mapa da Violência, menor apenas que a verificada em 2003, que foi de 22,2 mortes para cada $100 \mathrm{mil}$ habitantes. No caso específico dos homicídios praticados com armas de fogo, a taxa de mortalidade de $2012(20,7)$ é a mais elevada desde 1980 . Ao analisar o período de 2004 a 2012, o Mapa da Violência estima ainda que 160.036 vidas foram poupadas, em virtude da política de controle de armas, graças ao advento da Lei Federal $\mathrm{n}^{\circ}$ 10.826, de 22 de dezembro de 2003, conhecida como o Estatuto do Desarmamento (Brasil, 2003), que prevê o controle do uso de armas. Desse total de mortes evitadas, 113.071 foram de jovens, de acordo com a projeção.

O levantamento do Mapa da violência 2015: mortes matadas por armas de fogo (Waiselfisz, 2015) é o terceiro com foco em mortes ocorridas exclusivamente por disparo de armas de fogo. O primeiro foi divulgado em 2005 e o segundo, em 2013, com dados até 2010. A nova versão incorpora dados de 2011 e 2012. A fonte primária é o Sistema de Informação sobre Mortalidade (SIM) do Ministério da Saúde (Brasil, 2014), gerido pela Secretaria de Vigilância em Saúde e baseado nas declarações de óbito expedidas em todo o país. O levantamento registra o local das mortes e características das vítimas, como idade, cor e gênero.

O estudo de Waiselfisz (2015) revela também que os jovens são as maiores vítimas das mortes por armas de fogo no Brasil. Do total de 42.416 óbitos por disparo de armas de fogo em 2012, 24.882 foram de pessoas na faixa de 15 a 29 anos, o equivalente a $59 \%$. Em termos 
demográficos, os jovens correspondiam a pouco menos de $27 \%$ da população brasileira. Já a taxa de mortalidade de jovens por armas de fogo atingiu 47,6 para cada 100 mil habitantes, em 2012. Portanto, mais que o dobro da taxa registrada para a população total $(21,9)$.

Tanto a taxa quanto o número absoluto de jovens mortos por armas de fogo em 2012 são os mais altos já registrados pelo Mapa da Violência desde 1980. E ainda, de acordo com o mesmo Mapa, os dados desse mesmo ano interromperam um leve movimento de queda, que havia sido constatado em 2010 e 2011, no número de mortos e nas taxas de mortalidade por disparo de armas de fogo no país, na população em geral e na faixa de 15 a 29 anos (Waiselfisz, 2015).

Um balanço de todo o período coberto pela série histórica do Mapa da Violência revela que 880.386 pessoas morreram por disparo de arma de fogo entre 1980 e 2012, no Brasil, sendo que 747.760 foram assassinadas. O total de mortos por armas de fogo, em 1980, foi de 8.710 pessoas, o que significa que houve um aumento de $387 \%$ até 2012 , quando foram registrados 42.416 óbitos. A população brasileira, nesse mesmo período, cresceu cerca de $61 \%$ (Waiselfisz, 2015).

O levantamento realizado por Waiselfisz (2015) ainda destaca que o crescimento das mortes por armas de fogo na população total foi alavancado, de forma quase exclusiva, pelos homicídios, que cresceram 556,6\%, enquanto os suicídios com armas de fogo aumentaram $49,8 \%$ e as mortes acidentais caíram $26,4 \%$. As mortes por armas de fogo de causalidade indeterminada, isto é, sem especificação (suicídio, homicídio ou acidente) tiveram uma significativa queda $(-31,7 \%)$, evidenciando que houve melhoria nas investigações a esse respeito. Entre os jovens, o panorama foi mais drástico ainda: o crescimento de $463,6 \%$ no número de vítimas de armas de fogo explica-se de forma exclusiva pelo aumento de $655,5 \%$ dos jovens assassinados, enquanto acidentes, suicídios e casos indeterminados caíram ao longo do período (-23,2\%; $-2,7 \%$ e $-24,4 \%$ respectivamente).

A nova edição do Mapa da Violência 2015, segundo Waiselfisz (2015), também apresenta dados por região, estado, capitais e municípios, revelando situações distintas dentro do país. Enquanto o número de mortos por armas de fogo no Brasil, em números absolutos, aumentou $11,7 \%$, de 2002 a 2012, a região Sudeste teve queda de $39,8 \%$ nesse mesmo período, puxada pelos estados de São Paulo (- 58,6\%) e Rio de Janeiro (-50,3\%). As demais regiões tiveram aumento: $+135,7 \%$, no Norte; $+89,1 \%$, no Nordeste; $+34,6 \%$, no Sul; e $+44,9 \%$, no Centro-Oeste.
O estado com maior taxa de mortes por armas de fogo, em 2012, era Alagoas, com 55 óbitos para cada 100 mil habitantes. Roraima era o estado com menor taxa $(7,5)$. De 2002 a 2012, nove estados tiveram redução da taxa de mortes por armas de fogo. São Paulo teve a maior queda $(-62,2 \%)$. Outros 17 estados e o Distrito Federal registraram elevação. O Maranhão apresentou o maior aumento (273,2\%). Para Waiselfisz (2015), entre as capitais, Maceió (AL) apresentava a maior taxa de mortalidade por armas de fogo na população total, em $2012(79,9)$. Boa Vista (RR) tinha a menor taxa: 7,1. Doze capitais apresentaram redução na taxa, no período de 2002 a 2012. A cidade do Rio de Janeiro foi a que teve a maior queda $(-68,3 \%)$. São Luís (MA) teve a maior elevação $(+31,6 \%)$.

E ainda, conforme Waiselfisz (2015), o levantamento, ao mesmo tempo, calculou as taxas de mortalidade, na população total, de 1.669 municípios com mais de 20 mil habitantes no país. Para evitar que eventos isolados tenham peso desproporcional nas estatísticas municipais, o Mapa trabalha, para esses municípios, com a média de mortes por armas de fogo dos três últimos anos com dados disponíveis, isto é, 2010, 2011 e 2012.

No caso da população jovem, de 15 a 29 anos, foram considerados apenas os municípios com mais de 15 mil jovens, num total de 555 cidades brasileiras. O município de Simões Filho, no estado da Bahia, aparece com a maior taxa de mortalidade de armas de fogo no período, tanto na população total quanto entre os jovens. Na população total, Simões Filho teve 130,1 óbitos para cada 100 mil habitantes. Entre os jovens, a taxa atingiu 314,4 óbitos para cada 100 mil habitantes (Waiselfisz, 2015).

Já em relação ao chamado Índice de Vitimização Juvenil por Armas de Fogo (IVJ-AF), que analisa a incidência de homicídios na população jovem, comparando os resultados com os da população não jovem, o estudo de Waiselfisz (2015) revelou que, em 2012, em média, morreram proporcionalmente $285 \%$ mais jovens que não jovens por assassinato praticado com armas de fogo. Em outras palavras, para cada não jovem assassinado por arma de fogo, quase quatro jovens foram mortos da mesma maneira. No que se refere à idade das vítimas fatais por disparo de armas de fogo, em 2012, a mais alta taxa de mortalidade foi verificada entre os jovens de 19 anos, com taxa de 62,9 mortes para cada 100 mil habitantes. A segunda taxa mais alta $(62,5)$ atingiu os jovens de 20 anos. 
Além disso, de acordo com a investigação realizada por Waiselfisz (2015), as armas de fogo vitimaram 10.632 brancos e 28.946 negros no Brasil, o que representa 11,8 óbitos para cada 100 mil brancos e 28,5 para cada 100 mil negros. Logo, pode-se afirmar que morreram proporcionalmente $142 \%$ mais negros que brancos por armas de fogo. O levantamento revela também que, em 2012, 94\% das vítimas fatais de disparo de armas de fogo eram do sexo masculino, na população total. Entre os jovens, esse percentual chegava a $95 \%$. Também se comparou as taxas de mortalidade por armas de fogo de 90 países ou territórios, o Brasil ficou na $11^{a}$ posição, ou seja, com a $11^{\text {a }}$ taxa mais alta de mortalidade por armas de fogo no grupo de 90 países: 21,9 óbitos para cada 100 mil habitantes. A Venezuela lidera o ranking com taxa de 55,4 óbitos por armas de fogo. No extremo oposto, a Coreia do Sul, o Japão, Marrocos e Hong Kong aparecem com taxa zero de mortes por armas de fogo.

No período de 2001 a 2012, Pernambuco e sua capital, Recife, têm estado em evidência na mídia nacional e internacional, quando o tema central é a violência letal. O estado experimenta um complexo cenário de ocorrência desse tipo de violência: desde 2012, os indicadores de homicídios vêm sendo comparados aos de países que vivenciam situações de conflito armado (Geneva Declaration on Armed Violence and Development, 2011). No ano de 2002, Pernambuco estava na $26^{a}$ colocação com taxa de 54,8 por 100 mil habitantes, perdendo para o Rio de Janeiro com taxa de 56,5 por 100 mil habitantes; em pouco mais de dez anos, houve uma diminuição nacional com um índice de 37,1 por 100 mil habitantes em 2012, ficando ainda superior ao número nacional de mortalidade por homicídios que é de 29,0 por 100 mil habitantes. Em 2012, Recife apresentou taxas de assassinatos de 52,0 por 100 mil habitantes, também superior ao número nacional de homicídios nas capitais, que é de 38,5 por 100 mil habitantes (Waiselfisz, 2014).

Diante dessa epidemia de homicídios no Brasil com taxa de assassinatos de 56 mil mortos por ano, como explica Waiselfisz (2014), é preciso reexaminar urgentemente as práticas empregadas nessa conjuntura, na tentativa de implementar novos modelos dentro de uma realidade que comprovadamente não encontra resolutividade em si mesmo. Nesse sentido, o movimento conhecido como Justiça Restaurativa e, conforme os seus pressupostos e práticas, pode ser uma dessas possibilidades para enfrentarmos as dificuldades encontradas dentro desse quadro de intensa produção de violência armada.

\section{O Movimento Restaurativo e a Diminuição dos Homicídios}

Para Zehr (2012) o sistema penal é construído historicamente com base na culpabilidade do infrator, e a vítima, a parte desprezada, não tem poder de expressão, uma vez que o crime for cometido contra o Estado. Dessa forma, tem-se um quadro de insatisfação da vítima e de não ressocialização do ofensor.

O movimento jurídico conhecido como restaurativo iniciou-se na década de 1970. Ele surge trazendo críticas ao monopólio estatal da Justiça Criminal, ao uso dogmático do Direito Penal positivo, com foco apenas no infrator e na sua punição, entre outros posicionamentos, os quais foram sendo tomados pela chamada Justiça retributiva ou criminal (Souza, \& Züge, 2011). O primeiro país a implantar as práticas restaurativas foi a Nova Zelândia na década de 1970, a partir de um movimento da comunidade local (Brancher, 2014; Zehr, 1990). A Nova Zelândia aparece como pioneira no cenário internacional a introduzir a Justiça Restaurativa (JR) na legislação infanto-juvenil. Em 1989, a JR passa a ser utilizada para resolução dos casos da justiça juvenil e o tribunal é acionado somente em última opção ao jovem que comete um ato infracional no País. Entretanto, somente em 2002, a Organização das Nações Unidas - ONU (2002) passou a orientar os países-membros a adotarem práticas restaurativas, estabelecendo parâmetros, princípios e valores dessas práticas (Brancher, 2014; 2015; Filgueira, 2013; Prudente, 2010).

Nesse sentido temos o Poder Judiciário que passa a ter um papel essencial na vida social e política em nosso país. Desde a Constituição de 1988 (Brasil, 1988), o poder da Justiça no Brasil passou a ser também o poder das garantias individuais ou de minorias através da defesa da cidadania e dos direitos humanos, as mudanças constitucionais que exigem de juízes uma maior proximidade com a sociedade. Deixando as velhas estruturas que se mantinham fechadas, ou seja, a mão de ferro ou pouco-caso sobre pobres e negros, que são a imensa maioria no sistema prisional, o Judiciário necessita atender o clamor no que se refere aos direitos humanos dos menos favorecidos (Nascimento, 2014; Prudente, 2010).

Dessa forma, de acordo com Brancher (2015), na JR o Direito se volta mais para a condição de dignidade da existência humana do que para a preocupação com os processos punitivos concernentes ao transgressor. O questionamento se dá pelo envol- 
vimento das partes interessadas, daqueles que têm um vínculo emocional com as pessoas disputantes e que podem colaborar no sentido de agregar possíveis soluções, como é o caso direto da família. Nas situações de violência especificamente, a JR vem preconizar que se valorizem os núcleos comunitários como forma de apoio e restauração da cidadania. E ainda, para Brancher (2015), a JR é um olhar novo na forma de lidar com os conflitos e o crime, portanto:

[...] baseada no empoderamento e mobilização das partes envolvidas, com vistas à sua auto composição. Mais do que encontros entre ofensores, ofendidos e suas comunidades de apoiadores, no entanto, a aplicação prática dos princípios da Justiça Restaurativa condiciona uma profunda revisão crítica dos valores, posturas e métodos tradicionais se instalam, de forma mais ou menos inconsciente e automática, nessas situações (p. 1).

Analisando a Resolução $\mathrm{n}^{\circ} 2002 / 12$ da ONU (2002), que dispõe sobre a implementação de programas restaurativos em matéria criminal, ela determina de maneira bastante objetiva o que vem a ser um programa de JR. Desta forma, a Resolução cita algumas das formas de concretização dos processos restaurativos, elencando de maneira não exaustiva, quatro modos de aplicabilidade dos mesmos, a saber:

Processo restaurativo significa qualquer processo no qual, a vítima e o ofensor, e, quando apropriado, quaisquer outros indivíduos ou membros da comunidade afetados por um crime, participam ativamente nas questões oriundas do crime, geralmente com a ajuda de um facilitador. Os processos restaurativos podem incluir a mediação, a conciliação, a reunião familiar ou comunitária (conferencing) e círculos decisórios (sentencing circles) (ONU, 2002, p. 1).

Em vez de pensar em culpa, assumir responsabilidade; no lugar de perseguição, encontro; e de imposição, diálogo; castigo se transforma em reparação do dano, coerção por coesão social. Esses são os princípios da JR, uma prática jurídica ainda desconhecida por muitos no Brasil, mas com resultados promissores. Para Brancher (2015), 95\% das vítimas que adotaram os círculos de conciliação entre os 380 casos pesquisados pelo Juizado da Infância e Juventude de
Porto Alegre, aprovaram a prática. Em São Paulo e Brasília, o modelo também já tem uma performance aceitável. Temos, dessa forma, que as escolas públicas de São Paulo, especialmente as das cidades de Santos e Tatuí, praticam há alguns anos o programa JR, que institui grupos de reflexão para discutir atos violentos. A ação chegou a mais de 900 instituições do estado de São Paulo em 2015 e, conforme levantamento da Secretaria de Educação, em todos os espaços em que a JR foi posta em prática os resultados foram satisfatórios (Brancher, 2015).

Ferrão, Santos e Dias (2016) conduziram um estudo que objetivou apresentar um relato de experiência de profissionais da área da Psicologia, dentro de uma Unidade de Internação de adolescentes em conflito com a lei, utilizando a JR. Pretendeu-se relacionar práticas restaurativas com possibilidade de experiência exitosa ao Sistema Socioeducativo. O relato teve como cenário uma unidade de Atendimento Socioeducativo de uma cidade no interior do estado do Rio Grande do Sul. Os dados obtidos são frutos da experiência profissional das autoras e fazem parte de um estudo maior intitulado "Um Estudo dos Fatores de Risco e de Proteção em Jovens que Cumprem Medida Socioeducativa". Os resultados mostraram que as práticas restaurativas realizadas nesta instituição foram apenas os círculos de compromisso. O tema da JR, por ser novo e por não ter sido originalmente um modelo criado no cenário brasileiro, ainda não tem seus resultados e impactos avaliados.

Também a Pastoral Carcerária no Brasil tem utilizado a JR como um método para reverter os resultados desfavoráveis registrados até agora no sistema carcerário. A finalidade dessa nova forma de ver e praticar a justiça é prevenir e não deixar que aconteça a reincidência, que conforme levantamento do Departamento Penitenciário Nacional - Depen (Brasil, 2012a) e do Conselho Nacional de Justiça - CNJ (2014) é alta. O programa da JR também leva em conta a reparação à vítima de possíveis danos causados pelo autor do delito, diferente da Justiça retributiva cuja finalidade é punir o ofensor.

De acordo com Silveira (citado por Rodrigues, 2014), que é coordenador nacional da Pastoral Carcerária, a JR vem sendo debatida há mais de 10 anos pelas pastorais carcerárias disseminadas em diversos países, e há quase quatro anos a entidade resolveu trabalhar com ela também no Brasil. Foi realizada uma parceria com o Centro de Direitos Humanos e Educa- 
ção Popular de Campo Limpo-SP, e estão formando agentes pastorais, além dos agentes prisionais e reeducandos a fazerem parte dos cursos realizados pela Pastoral Carcerária.

Silveira (citado por Rodrigues, 2014, p. 29) esclarece qual é o modelo de JR defendida pela Pastoral Carcerária que ele coordena: “[...] queremos criar comunidades fora do Judiciário, que evitem que a pessoa seja julgada por esse sistema. A sociedade deve se empoderar para impedir que os casos cheguem ao Judiciário". E ainda, a melhor forma de se aplicar a JR é fora da esfera do Poder Judiciário, ele exemplifica um dos casos intermediado pela Pastoral Carcerária:

[...] em Cascavel, no Paraná, houve o furto de um celular em uma escola. Chamaram a Pastoral Carcerária e nós convocamos os jovens, a família, os alunos e os professores. Um dos jovens envolvidos decidiu carpir o mato em volta da escola e o outro quis pintar a escola. A decisão de reparar o que fizeram foi deles. O Ministério Público reconheceu o ato e não levou o caso para o Judiciário. O processo de restauração aconteceu na comunidade (Silveira, citado por Rodrigues, 2014, p. 29).

Assim, o mesmo delito poderia levar os jovens para prisão se fosse encaminhado para o Sistema Judiciário tradicional. Um fato parecido ao do Paraná se deu na capital paulista, em que um jovem acusado de ter roubado um celular e um boné está preso há meses no Centro de Detenção Provisória de Pinheiros, na zona oeste da capital paulista, apesar do esforço da família para libertar o rapaz. A apelação do advogado já foi rejeitada em primeira e segunda instância e pelo Superior Tribunal de Justiça. O jovem segue preso, engrossando a massa de encarcerados do País (Rodrigues, 2014).

Brancher (2015) defende a ideia de que a JR não deve ser aplicada a todos os crimes, em cumprimento à Constituição Federal de 1988 que traz no seu art. 5º, inciso XLIII (Brasil, 1988), a previsão de tratamento mais severo aos crimes de tortura, tráfico de entorpecentes e drogas afins, o terrorismo e os crimes definidos como hediondos, pela natureza e gravidade das infrações, bem como pelo perfil e a alta periculosidade apresentada pelos infratores que praticam estes crimes.

Considerando-se a importância, a atualidade e a gravidade do problema do homicídio, buscou-se contribuir para as discussões que enfocam a questão dessa causa de morte, muitas vezes, precoce, na população pernambucana. Sendo assim, o estudo objetivou avaliar a tendência temporal e a magnitude dos homicídios no estado de Pernambuco, no período entre 2009 e 2014, e analisar seus diferenciais quanto ao sexo e faixa etária. Ao mesmo tempo se propõe a prática da JR como forma de prevenir e enfrentar o problema dos homicídios e, consequentemente, da violência. Por ser novo, e por não ter sido originalmente um modelo criado no cenário brasileiro, ainda é difícil de avaliar possíveis resultados e impactos.

\section{Método}

Foi utilizado um desenho ecológico exploratório do tipo série temporal com dados de óbitos por homicídios levantados do sítio eletrônico da Secretaria de Defesa Social de Pernambuco, Sistema de Informações Policiais (Pernambuco, 2015). Procedeu-se à padronização dos coeficientes por idade, pelo método direto, não sendo encontradas diferenças em relação aos dados não padronizados, indicando que as alterações nos indicadores eram independentes da mudança da estrutura etária da população. Concluiu-se, então, ser desnecessário o uso dos valores padronizados para a elaboração da tendência temporal.

Segundo dados do censo demográfico de 2010, disponibilizados pela Fundação Instituto Brasileiro de Geografia e Estatística - IBGE (2010), o estado de Pernambuco possui uma extensão territorial de $98.146 .315 \mathrm{~km}^{2}$ e população de 8.796 .448 habitantes, dos quais 4.230.681 (48,09\%) eram do sexo masculino; $25,65 \%$ da população geral possuíam menos de 14 anos de idade, $27,40, \%$, de 15 a 29 anos, $36,27 \%$, de 30 a 59 anos, e 10,66\%, 60 anos e mais; a raça/cor predominante era parda $(55,3)$ e $80,2 \%$ de seus habitantes residiam em área urbana.

O estado de Pernambuco possui importantes diferenças sociais, tendo um dos Índices de Desenvolvimento Humano (IDH) mais baixos do país. Segundo o Programa das Nações Unidas para o Desenvolvimento (PNUD) (Atlas do desenvolvimento humano no Brasil, 2010), em 2010, o estado apresentou um IDH igual a 0,673 , ocupando a $19^{a}$ posição no ranking entre os demais estados e o Distrito Federal. No mesmo ano, o IDH municipal (IDH-M) referente à renda foi igual a 0,637, o IDH-M saúde, 0,789, e o IDH-M educação, 0,574 (Freire, Cirne, Araújo, Andrade, \& Oliveira, 2008; Atlas do desenvolvimento..., 2010). Apesar do acréscimo significativo na renda média domiciliar per capita, aumento nos níveis de escolaridade e redu- 
ção do analfabetismo, ocorridos ao longo dos últimos anos, a pobreza ainda ocupa patamares expressivos em Pernambuco.

Foram estudados os registros de homicídios ocorridos no estado no período de $1^{\circ}$ de janeiro de 2009 a 31 de dezembro de 2014, em relação às variáveis sexo e faixa etária. Infelizmente deixamos de incluir as variáveis raça/cor, estado civil, escolaridade e ocupação das vítimas por não terem sidos registrados pelo Sistema de Informações Policiais da Secretaria de Defesa Social de Pernambuco - Infopol/SDS-PE (Pernambuco, 2015).

A escolha dos estratos para a variável faixa etária ( 0 a 14, 15 a 29, 30 a 59 e 60 anos e mais) deve-se aos diferentes ciclos da vida, bem como à semelhança de comportamento no perfil de mortalidade por causas violentas e outras causas definidas pelo Ministério da Saúde, para análise da mortalidade (Brasil, 2013).

Foram calculadas as taxas de mortalidade acumulada para o período do estudo, tendo por numerador a soma dos homicídios ocorridos no período, e por denominador, a média da população residente para o mesmo período. Com o propósito de definir a população residente no estado, utilizou-se o método para projeções estaduais adotado pelo IBGE, ou seja, de projeção da tendência do crescimento demográfico (Freire et al., 2008).

Também foram calculadas as taxas de mortalidade específicas para ano, sexo e faixa etária, tendo por numerador os homicídios por ano, sexo ou faixa etária, e, por denominador, a população por ano, sexo ou faixa etária, por 100 mil habitantes. Para o cálculo da taxa de mortalidade acumulada, dadas as dificuldades em obter o número de pessoas expostas ao risco de morte por homicídio em Pernambuco, optou-se por utilizar a população residente no estado.

Os dados sobre a população residente foram levantados do sítio eletrônico do Departamento de Informática do Sistema Único de Saúde de 2009 a 2012, administrado pelo Ministério da Saúde, e das estimativas do Tribunal de Contas da União de 2013 e 2014, cujas fontes referem o IBGE (Brasil, 2014). Também foi calculada a mortalidade proporcional por sexo e faixa etária, tendo por numerador os homicídios por sexo e faixa etária do homicídio, e por denominador, o total de homicídios.

Foram utilizados os programas Microsoft Office Excel $^{\circledR}$ (versão 2007), para análise de regressão, e os software Epi Info ${ }^{\mathrm{TM}}$ (versão 3.5.2) e Epi Info versão 6.04, para cálculo da razão de risco entre os sexos (com os intervalos de confiança). Essa razão mensura a frequência dos homicídios nos homens em relação ao grupo de mulheres, mostrando a proporcionalidade entre os sexos, da ocorrência do evento em análise. As populações consideradas no cálculo dos coeficientes de mortalidade foram estimadas pelo método geométrico, a partir da contagem populacional do Censo 2000 realizado pelo IBGE (2010).

A pesquisa respeitou as exigências éticas da Resolução ${ }^{\circ}$ 466/2012 do Ministério da Saúde, Diretrizes e normas regulamentadoras de pesquisas envolvendo seres humanos preservando a identidade das vítimas (Brasil, 2012b).

\section{Resultados}

Foram registrados 20.891 homicídios no período de 2009 a 2014, representando uma média de 3.481,8 homicídios/ano, como estão descritos na Tabela 1. O registro de média mensal foi de 290,1 homicídios, ou, mais precisamente, de 96,7 registros/dia.

As taxas de homicídios por 100 mil habitantes variaram de 39,1 óbitos em 2014 a 35,2 óbitos em 2013. A maioria dos óbitos por homicídios ocorreu no sexo masculino $(92,6 \%)$. Entre as mulheres, verificou-se um decréscimo nas taxas de homicídio de $18,1 \%$ entre 2009 e 2014 . Neste mesmo período, a taxa de homicídios acumulada para o sexo masculino foi de 547,3/100 mil habitantes, e para o feminino, de 33,9/100 mil habitantes. A razão entre as taxas (masculino/feminino) variou de 13,4 em 2014 a 13,3 em 2009, sendo que a razão das taxas acumuladas de 13,5 estão apresentados na Tabela 1.

A maioria dos homicídios $(56,1 \%)$ vitimou adolescentes ou adultos jovens ( 15 a 29 anos) de ambos os sexos. Observou-se 1,3\% dos óbitos (274) na faixa etária menor de 14 anos, como está registrada na Tabela 2, embora não houvesse dados sobre essa variável em $1,7 \%$ dos registros.

É importante salientar que, ao compararmos os dados relacionados às taxas de homicídios por 100 mil habitantes, para ambos os sexos, para os anos de 2009 a 2012, fornecidos pela Tabela 1, os quais são: 45,7; 39,9; 39,8 e 37,7 respectivamente, e os de Waiselfisz (2014) durante os mesmos anos de 2009 a 2012, que são: 44,9; 39,3; 39,1 e 37,1 respectivamente, eles praticamente foram os mesmos para os dois levantamentos. 
Tabela 1

Distribuição do número de óbitos e taxas de homicídios por sexo e na população geral e razão de risco entre os sexos por ano de ocorrência do óbito em Pernambuco, Brasil, de 2009 a 2014.

\begin{tabular}{|c|c|c|c|c|c|c|c|}
\hline \multirow{2}{*}{$\begin{array}{l}\text { Ano do } \\
\text { óbito }\end{array}$} & \multicolumn{3}{|c|}{$\begin{array}{l}\text { Número } \\
\text { de óbitos }\end{array}$} & \multicolumn{3}{|c|}{$\begin{array}{c}\text { Taxa de homicídio } \\
\text { (por } 100 \text { mil habitantes) }\end{array}$} & \multirow{2}{*}{$\begin{array}{c}\begin{array}{c}\text { Razão } \\
\text { de risco }\end{array} \\
\begin{array}{c}\text { Masculino } \\
\text { feminino }\end{array}\end{array}$} \\
\hline & $\begin{array}{c}\text { Sexo } \\
\text { feminino }\end{array}$ & $\begin{array}{c}\text { Sexo } \\
\text { masculino }\end{array}$ & $\begin{array}{l}\text { Ambos os } \\
\text { sexos }\end{array}$ & $\begin{array}{c}\text { Sexo } \\
\text { feminino }\end{array}$ & $\begin{array}{c}\text { Sexo } \\
\text { masculino }\end{array}$ & $\begin{array}{l}\text { Ambos os } \\
\text { sexos }\end{array}$ & \\
\hline 2009 & 300 & 3.718 & 4.018 & 6,6 & 87,9 & 45,7 & 13,3 \\
\hline 2010 & 245 & 3.263 & 3.508 & 5,4 & 77,1 & 39,9 & 14,2 \\
\hline 2011 & 274 & 3.232 & 3.506 & 6 & 76,4 & 39,8 & 12,7 \\
\hline 2012 & 213 & 3.107 & 3.320 & 4,7 & 73,4 & 37,7 & 15,6 \\
\hline 2013 & 256 & 2.847 & 3.103 & 5,6 & 67,3 & 35,2 & 12 \\
\hline 2014 & 254 & 3.182 & 3.436 & 5,6 & 75,2 & 39,1 & 13,4 \\
\hline Total & 1.542 & 19.349 & 20.891 & 33,9 & 457,3 & 237,5 & 13,5 \\
\hline
\end{tabular}

Tabela 2

Número e distribuição proporcional (\%) dos homicídios por sexo e faixa etária em Pernambuco, Brasil, de 2009 a 2014.

\begin{tabular}{lcc}
\hline Variáveis & $\mathrm{N}$ & $\%$ \\
\hline Sexo & & \\
$\quad$ Masculino & 19.349 & 92,61 \\
Feminino & 1.542 & 7,38 \\
Faixa etária (em anos) & & \\
$0-14$ & 274 & 1,3 \\
$15-29$ & 11.716 & 56,1 \\
30-59 & 7.898 & 37,8 \\
60 e mais & 638 & 3 \\
Sem informação & 365 & 1,7 \\
\hline
\end{tabular}

\section{Discussão}

No período de 2009 a 2014, foram evidenciadas elevadas taxas de homicídio em Pernambuco, com uma variação de 37,7/ 100 mil habitantes em 2012 para 39,1 em 2014 - com destaque para a taxa de 45,7/100 mil habitantes em 2009. Esses valores são superiores àqueles observados para o Brasil, com taxas de homicídios/100 mil habitantes de 27,1 em 2010, 27,5 em 2011 e de 25,8 em 2012. Os dados apresentados fazem com que o estado de Pernambucano esteja no topo do ranking dos estados mais violentos do Brasil e do mundo (UNODC, 2013; Waiselfisz, 2013; 2014).

Aproximadamente 92,6\% dos homicídios ocorreram na população masculina. Resultados semelhantes são citados em outros estudos (Campos, Ferreira,
Barros, \& Silva, 2011; Waiselfisz, 2015). Os dados de mortalidade acumulada para ambos os sexos e mortalidade específica para as causas básicas de morte revelam uma intensa produção da violência armada, a demandar abordagens diferenciadas nas ações das políticas públicas de prevenção e de enfrentamento da criminalidade letal.

Esses dados corroboram a afirmação de que a violência em Pernambuco vitimiza especialmente homens e jovens. Vale ressaltar o decréscimo na taxa de homicídio no sexo feminino, ao considerar o início e o final do estudo. A variação nessa taxa foi de $18,1 \%$, graças ao advento da Lei Federal $n^{\circ} 11.340$, de 7 de agosto de 2006 (Brasil, 2006), conhecida como Lei Maria da Penha para proteger e coibir a violência contra as mulheres.

Em um estudo denominado "Como morrem os brasileiros: ranking e tendências das taxas de mortalidade por grupo de causas no Brasil e regiões, 2000 a 2011", da Secretaria de Vigilância em Saúde (Brasil, 2013), sobre o perfil de mortalidade no Brasil, foram constatados que as agressões são a primeira causa de morte em jovens do sexo masculino entre 10 e 29 anos, no país e em sua macrorregião Nordeste; e a segunda e terceira causa de mortes no sexo feminino, respectivamente no país e no Nordeste. Walselfisz (2014) observa que Pernambuco continua o processo de queda em 2012 - diminuiu 6,8\% - mas ainda com níveis altos de assassinatos de jovens: 73,8 homicídios por $100 \mathrm{mil}$ jovens para o período de 2002 a 2012. Para o mesmo período o estado do Rio Grande do Norte, que lidera a lista com a maior taxa de homicídios de jovens do Brasil, apresentou 293,6 homicídios por 100 mil jovens. 
Por outro lado, a maioria dos homicídios do presente estudo ocorreu com indivíduos adolescentes e jovens entre 15 e 29 anos, correspondendo a 56,1\% (11.716) dos assassinatos, média de 1.952,6 óbitos por ano. Comparando-se esses dados com a realidade do conjunto do país, a média pernambucana está alta em relação à média nacional, que é de 39,3\% (Waiselfisz, 2013).

Em um estudo sobre a violência letal na cidade de Maceió (AL), Alves, Correia, Barbosa, Lopes e Melânia (2014), entre os anos de 2007 a 2012, constataram 5.735 homicídios no período, correspondendo à média de 955,8 homicídios/ano, com taxas que variaram de 89,6 óbitos/100 mil habitantes (2012) a 111,4 óbitos/100 mil habitantes (2011). E ainda, $94,8 \%$ das vítimas eram do sexo masculino, $66,2 \%$ eram jovens de 15 a 29 anos e $79,9 \%$ da raça/cor parda; os homicídios ocorreram, majoritariamente, nos períodos noturnos e de madrugada (51,5\%), com envolvimento de arma de fogo $(87,8 \%)$. Para Mansano, Gutierrez, Ramalho e Duarte (2013), alguns dos fatores capazes de justificar esses dados são: a maior exposição dos jovens a comportamentos de risco e o fato de esses mesmos jovens viverem em comunidades de áreas mais pobres, com sérios problemas de exclusão juvenil e desigualdade social.

Waiselfisz (2013), também nos remete à desigualdade social, ao abordar estudos que apontam que a maioria dos óbitos $(80,2 \%)$, refere-se à população de raça/cor de pele negra, esses resultados podem ser consequência da desigualdade social, como também do preconceito e discriminação entre segmentos da sociedade. Dentro da sociedade geral, grupos discriminados ocupam uma posição de desvantagem, desvalorização e maior exposição a riscos.

A análise dos dados dos homicídios registrados no Sistema Infopol/SDS-PE (Pernambuco, 2015), ocorridos no estado de Pernambuco, revela um perfil de mortalidade semelhante ao padrão nacional e regional: predominantes vítimas jovens, do sexo masculino, causado por arma de fogo, como indicam vários estudos (Almeida, no prelo; Alves et al., 2014; Brasil, 2013; Faraj, Siqueira, \& Arpini, 2016; FGV, 2012; UNODC, 2013; Waiselfisz, 2013; 2014; 2015).

Acredita-se que a perda dos jovens para os subprodutos da criminalidade terá graves consequências futuras: do ponto de vista demográfico e econômico, é possível afirmar que a geração de jovens afetados observada, economicamente ativa, não contribuirá com a economia nacional como poderia. Segundo a Política
Nacional de Atenção Integral à Saúde do Homem, mortes prematuras trazem implicações psicofísicas e socioeconômicas enquanto vidas jovens perdidas em plena fase produtiva (Almeida, 2013; Waiselfisz, 2015).

Temos então que o estado de Pernambucano se destaca entre os lugares com maior risco de morte por assassinatos no país. A criminalidade manifestada no estado não se resume às questões quantitativas, e sim, à sua abrangência e complexidade, reveladas pela alta mortalidade por violência. Os homicídios, portanto, mostra a face visível de uma realidade grave e complexa, e que nos últimos anos, vem sendo atribuído a um grande conjunto de fatores, dentre os quais se destacam a desigualdade social, a corrupção e a impunidade. (Brasil, 2013; FGV, 2012).

Infelizmente o Brasil assumiu recentemente o terceiro lugar no pódio de países que mais encarceraram no mundo, desbancando a Rússia, ficando atrás dos Estados Unidos e da China, com os números anunciados pelo CNJ (2014), que indicam uma população carcerária superior a 700 mil detentos, ou seja, 358 detentos para cada 100 mil habitantes. No comparativo com o Brasil, a Argentina tem número ainda mais baixo, são 149 detentos por 100 mil pessoas (CNJ, 2014).

Um levantamento promovido pelo Depen (Brasil, 2012a), durante o ano de 2012, traçou o perfil dos detentos que lotam os presídios no Brasil e quais crimes cometeram, dando um panorama do sistema prisional. Ao que tudo indica, a Justiça tende a condenar mais os pobres e negros. Para o Depen, a população carcerária nos presídios brasileiros reforça essa realidade, pois a sua maioria é composta por pardos ou negros e possui baixa escolaridade, reforçando a cada dia uma verdadeira "higienização social", na qual nossos presídios são comparados aos campos de concentração nazistas.

Dessa forma, em uma sociedade em que a distribuição de renda não seja tão injusta e que a corrupção e a impunidade sejam combatidas, em que a educação é levada a sério, o número da violência e dos homicídios tende a diminuir drasticamente, é o que observamos em alguns países europeus (Gomes, 2014).

Neste sentido, a JR é um modelo de resolução de conflitos e dos crimes, por outro lado, ela deve ser aplicada em parceria com o Poder Judiciário apenas aos crimes de médio e pequeno potencial lesivo e aos atos infracionais envolvendo jovem infrator (Ferrão et al., 2016). Esta constatação decorre da maior chance de viabilidade, dada uma maior possibilidade de participação da vítima e dos seus familiares e em razão de uma maior 
probabilidade de aceitação por parte do infrator, além de maiores chances de que o mesmo assuma a responsabilidade pelo crime praticado e busque a satisfação dos interesses e necessidades da vítima, conduzindo a uma provável não reincidência criminal.

Por outro lado, os principais limites e os desafios na prática da JR, inicialmente, são os culturais. Assim, abdicar dos costumes é um entrave a toda e qualquer mudança. Um segundo grupo de limites, de acordo com Brancher (2015), são operacionais:

[...] o procedimento é muito sofisticado. Exige uma atuação personalizada, artesanal, incompatível com o processamento massivo dos conflitos que é a realidade do Judiciário de hoje (...). A roda viva da vida, a mesma que roda automaticamente, produzindo e reproduzindo a violência, não abre espaço para a escuta e para o encontro (p. 1).

Temos assim que a JR pode contribuir para os direitos humanos e o fortalecimento de uma cultura de paz e para o enfrentamento do homicídio e dos conflitos nos mais distintos espaços da sociedade (Azevedo, \& Pallamolla, 2014; Brancher, 2014; 2015; Prudente, 2010; Zehr, 2012). E ainda, para Nascimento:

[...] nós - os psicólogos - somos conclamados a sermos autênticos no combate à violência e às várias formas de opressão impostas aos seres humanos, assim como na luta pelas ações afirmativas na perspectiva dos direitos humanos. Afinal, também disso são feitas nossa ciência e nossa profissão (2014, p. 244).

\section{Considerações Finais}

As limitações encontradas no desenvolvimento do presente estudo referem-se ao uso de dados secundários, sobretudo às proporções de campos sem preenchimento para algumas variáveis, e à própria cobertura do Infopol/SDS-PE (Pernambuco, 2015). Todavia, os dados permitiram caracterizar parcialmente o perfil e a magnitude da letalidade violenta em Pernambuco. Outra limitação deste estudo remete à exclusão dos registros das variáveis como raça/cor, estado civil, escolaridade e ocupação das vítimas, pelo motivo de não terem sidos fornecidos pelo Infopol/SDS-PE (Pernambuco, 2015), visto que a não inclusão de tais variáveis prejudica a observação do perfil sociodemográfico do estudo. O levantamento em tela revela que o estado de Pernambuco tem altas taxas de homicídios, registrando um aumento no ano de $2014 \mathrm{em}$ comparação aos anos de 2012 e 2013.

A amplitude exacerbada da violência letal torna evidente a necessidade de mais estudos para investigar o tema sob diferentes olhares, dirigidos a suas vítimas e autores, abordando as políticas públicas intersetoriais (focadas na prevenção e combate à violência), assim como o Sistema de Justiça Criminal brasileiro e a questão da impunidade desses crimes.

Sugere-se que os resultados obtidos e os estudos aqui apresentados, além dos realizados por outros autores referentes ao tema e referenciados neste, sejam utilizados como auxílio para o diálogo interdisciplinar, como mencionado na introdução deste estudo, sobre questões no que diz respeito à violência e à segurança, os quais devem deixar de serem objetos particulares da segurança pública e da justiça criminal, passando a ser tratadas como problemas sociais, com verberações na área da saúde, educação e cultura, e de melhoria de políticas públicas inclusivas, e também na concretização de estratégias de prevenção e controle da violência no estado de Pernambuco.

Não se pode ignorar, a redução da mortalidade por homicídios não é tarefa simples. Trata-se de um problema relacionado a diversos fatores individuais, sociais, econômicos, culturais, entre outros. Sugere-se que outros estudos possam descrever a magnitude desses eventos no tempo e seus diferenciais, além da idade e do sexo aqui apresentados, como a raça/cor, estado civil, escolaridade e ocupação das vítimas, podendo estes contribuírem para a prevenção das mortes violentas por meio da detecção de grupos vulneráveis aos vários fatores envolvidos nessas agressões.

A mortalidade por homicídios reduz a esperança de vida ao nascer, principalmente para o sexo masculino, concorrendo para um efeito contrário ao que se observa com a redução da mortalidade infantil. Os ganhos obtidos pela redução da mortalidade na infância e consequente aumento do número de anos de vida da população são anulados pelo efeito das causas externas.

No caso de Pernambuco, ação específica frente aos homicídios devem se voltar, principalmente, a adolescentes e adultos jovens, grupo que vem mantendo, ao longo do tempo, os altos níveis dos indicadores de mortalidade. Também é importante considerar que, a despeito de o sexo masculino ser o mais atingido, 
a decrescente ocorrência de homicídios no sexo feminino aponta, igualmente, para a necessidade de continuação de intervenção nesse segmento da população.

É nesse panorama que aparece uma opção a esse poder penal sobre os homicídios, a chamada JR, que tem sido definida como uma nova forma de lidar com a questão dos conflitos e dos crimes. Apresenta-se como uma alternativa à lógica da retribuição e punição presente no sistema de justiça tradicional e também na sociedade contemporânea. Centrando-se nas pessoas e nos relacionamentos, busca promover intervenções focadas na reparação dos danos, no atendimento das necessidades, na responsabilização dos ofensores, visando o restabelecimento dos vínculos sociais e das comunidades. Por ser um paradigma novo e ainda principiante no panorama brasileiro, verifica-se a necessidade de mais estudos científicos que abordem a temática da JR em nossa sociedade brasileira.

\section{Referências}

Almeida, N. D. V. (2013). A saúde no Brasil, impasses e desafios enfrentados pelo Sistema Único de Saúde (SUS). Revista Psicologia e Saúde, 5(1), 1-9. Recuperado de http://pepsic.bvsalud.org/scielo.php?script=sci_arttext\&pi$\mathrm{d}=\mathrm{S} 2177-093 \mathrm{X} 2013000100002$

Almeida, N. D. V. (no prelo). Adolescente em conflito com a lei e a redução da maior idade penal. Psicologia: Ciência e Profissão.

Alves, W. A., Correia, D. S., Barbosa, L. L. B., Lopes, L. M., \& Melânia, M. I. A. (2014). Violência letal em Maceió-AL: estudo descritivo sobre homicídios, 2007-2012. Epidemiologia e Serviços de Saúde, 23(4), 731-740. https://doi.org/10.5123/S1679-49742014000400015

Atlas do desenvolvimento humano no Brasil. (2010). Ranking: todo o Brasil (2010). Brasília, DF: o autor. Recuperado de http://atlasbrasil.org.br/2013/ranking

Azevedo, R. G., \& Pallamolla, R. P. (2014). Alternativas de resolução de conflitos e justiça restaurativa no Brasil. Revista da Universidade de São Paulo, (101), 173-184.

Brancher, L. (2014). A paz que nasce de uma nova justiça: paz restaurativa: 2012-2013: um ano de implantação da justiça restaurativa como política de pacificação social em Caxias do Sul. Recuperado de https://www.tjrs.jus.br/ export/processos/conciliacao/doc/A_Paz_que_Nasce_de_uma_Nova_Justica_BAIXA.pdf

Brancher, L. (2015). Entrevista exclusiva do Dr. Leoberto Brancher para o site Responsabilidade Social. Recuperado de http://www.justica21.org.br/j21.php?id=440\&pg=0\#.VQnIZdLF-d4

Brasil. (1988, 5 de outubro). Constituição da República Federativa do Brasil de 1988. Diário Oficial da União.

Brasil. (2003, 23 de dezembro). Lei No 10.826, de 22 de dezembro de 2003. Dispõe sobre registro, posse e comercialização de armas de fogo e munição, sobre o Sistema Nacional de Armas - Sinarm, define crimes e dá outras providências. Diário Oficial da União.

Brasil. (2006, 8 de agosto). Lei No 11.340, de 7 de agosto de 2006. Cria mecanismos para coibir a violência doméstica e familiar contra a mulher, nos termos do $\$ 80$ do art. 226 da Constituição Federal, da Convenção sobre a Eliminação de Todas as Formas de Discriminação contra as Mulheres e da Convenção Interamericana para Prevenir, Punir e Erradicar a Violência contra a Mulher; dispõe sobre a criação dos Juizados deViolência Doméstica e Familiar contra a Mulher; altera o Código de Processo Penal, o Código Penal e a Lei de Execução Penal; e dá outras providências. Diário Oficial da União.

Brasil. (2013). Ministério da Justiça. Associação Cultural e de Pesquisa Noel Rosa. Mortes violentas no Brasil: uma análise do fluxo de informações. In I. S. Figueiredo, C. Neme, \& C. S. L. Lima (Orgs.), Homicídios no Brasil: registro e fluxo de informações. Brasília, DF: o autor.

Brasil. (2012a). Ministério da Justiça. Departamento Penitenciário Nacional-DEPEN. Plano diretor de melhorias para o sistema prisional. Recuperado de http://www.justica.gov.br/seus-direitos/politica-penal/arquivos/plano-diretor/anexos-plano-diretor/plano-diretor-de-melhorias-para-o-sistema-prisional.pdf

Brasil. (2014). Ministério da Saúde. Departamento de Informática do SUS. Informações de saúde (Tabnet). Demográficas e socioeconômicas. Brasília, DF: o autor.

Brasil (2012b). Ministério da Saúde. Resolução No 466, de 12 de dezembro de 2012. Diretrizes e normas regulamentadoras de pesquisas envolvendo seres humanos. Recuperado de http://bvsms.saude.gov.br/bvs/saudelegis/ cns/2013/res0466_12_12_2012.html 
Campos, M. E. A. L., Ferreira, L. O. C., Barros, M. D. A., \& Silva, H. L. (2011). Mortes por homicídio em município da Região Nordeste do Brasil, 2004-2006 a partir de dados policiais. Epidemiologia e Serviço de Saúde, 20(2), 151-9. https://doi.org/10.5123/S1679-49742014000400015

Conselho Nacional de Justiça - CNJ. (2014). Departamento de Monitoramento e Fiscalização doSistema Carcerário e do Sistema de Execução de Medidas

Socioeducativas - DMF. Novo diagnóstico de pessoas presas no Brasil. Brasília, DF: Autor. Recuperado de http:// www.cnj.jus.br/images/imprensa/diagnostico_de_pessoas_presas_correcao.pdf

Faraj, S. P., Siqueira, A. C ,\& Arpini, D. M. (2016). Notificação da violência: percepções de operadores do direito e conselheiros tutelares. Psicologia: Ciência e Profissão, 36(4), 907-920. https://doi.org/10.1590/1982-3703000622014

Ferrão, I. S., Santos, S. S., \& Dias, A. C. G. (2016). Psicologia e práticas restaurativas na socioeducação: relato de experiência. Psicologia: Ciência e Profissão, 36(2), 354-363. https:/ /doi.org/10.1590/ 1982-3703000122014

Filgueira, E. B. F. (2013). Justiça restaurativa no sistema penal e processual penal como forma de concretização do estado democrático constitucional (Dissertação de mestrado). Universidade Federal do Rio Grande do Norte, Natal, RN.

Freire, F. H. M., Cirne, R. C. B. A., Araújo, F. H. M., Andrade, R. C. B., \& Oliveira, J. M. (2008). Projeção populacional intra-urbana para 2020 da Região Metropolitana de Natal. In Anais do $16^{\circ}$ Encontro Nacional de Estudos Populacionais; Caxambu, MG. São Paulo: Unicamp. Recuperado de http://www.abep.nepo.unicamp.br/encontro2008/ docspdf/ABEP2008_1584.pdf

Fundação Getúlio Vargas - FGV (2012). Escola de Direito de São Paulo. O homicídio em três cidades brasileiras. In Figueiredo, I. S., Neme, C., \& Lima, C. S. L. (Orgs.), Homicídios no Brasil: registro e fluxo de informações (pp. 9-70; Coleção Pensando a segurança pública, Vol. 1). Brasília, DF: Ministério da Justiça.

Geneva Declaration on Armed Violence and Development. (2011). Global burden of armed violence 2011. Geneva: o autor. Recuperado de http://www.genevadeclaration.org/measurability/global-burden-of-armed-violence/ global-burden-of-armed-violence-2011.html

Gomes, L. F. (2014). Suécia e Holanda fecham prisões. Brasil fecha escolas e abre presídios. Jusbrasil. Recuperado de http://professorlfg.jusbrasil.com.br/artigos/121932808/suecia-e-holanda-fecham-prisoes-brasil-fecha-escolas-e-abre-presidios

Instituto Brasileiro de Geografia e Estatística - IBGE. (2010). Censo 2010. Rio de Janeiro, RJ: IBGE. Recuperado de http://www.censo2010.ibge.gov.br/

Krug, E. G., Dahlberg, L. L., Mercy, J. A., Zwi, A. B., \& Lozano, R. (2002). Relatório mundial sobre violência e saúde. Genebra: Organização Mundial da Saúde. Recuperado de https://www.opas.org.br/wp-content/uploads/2015/09/relatorio-mundial-violencia-saude.pdf

Mansano, N. H., Gutierrez, M. M., Ramalho, W., \& Duarte, E. C. (2013). Homicídios em homens jovens de 10 a 24 anos e condições sociais em municípios do Paraná e Santa Catarina, Brasil, 2001 - 2010. Epidemiologia e Serviço de Saúde, 22(2):203-14. https:// doi.org/10.5123/S1679-49742013000200002

Minayo, M. C. S. (2005). Violência: um velho-novo desafio para a atenção à saúde. Revista Brasileira de Educação Médica, 29(1), 55-63. Recuperado de http://www.bvsde.paho.org/bvsacd/cd51/desafio.pdf

Nascimento, A. F., \& Morais Neto, O. L. (2013). Como morrem os brasileiros: ranking e tendências das taxas de mortalidade por grupo de causas no Brasil e regiões, 2000 a 2011. Brasil. Minsitério da Saúde. Secretaria de Vigilância em Saúde. Saúde Brasil 2012: uma análise da saúde e dos 40 anos do Programa Nacional de Imunizações (pp. 203-14). Brasília, DF: Ministério da Saúde.

Nascimento, M. L. V. (2014). A Psicologia e as problemáticas relacionadas à violência e aos direitos humanos: o papel e o posicionamento do psicólogo. Revista de Ciências Humanas, 48(2), 234-246. https://doi.org/10.5007/2178-4582.2014v48n2p234

Organização das Nações Unidas (2002). Resolução 2002/12 de 24 de julho de 2002. Princípios básicos para utilização de programas de justiça restaurativa em matéria criminal. Genebra: o autor. Recuperado de http://www. justica21.org.br/j21.php?id=366\&pg=0\#.VqOt7tIrLMx

Peres, M. F. T., Ruotti, C., Carvalho, D., \& Regina, F. L. (2015). Vitimização fatal de crianças no espaço público em decorrência da violência interpessoal comunitária: um diagnóstico da magnitude e contextos de vulnerabilidade na América Latina. Revista Brasileira de Segurança Pública, 9(2), 12-48. Recuperado de http://revista.forumseguranca.org.br/index.php/rbsp/article/view/497 
Psicologia: Ciência e Profissão Jul/Set. 2017 v. 37 n³, 565-578.

Pernambuco (Estado). (2015), Secretaria de Defesa Social de Pernambuco. Sistema de Informações Policiais INFOPOL/SDS-PE. Gerência de Análise Criminal e Estatística. Relação nominal das vítimas de crimes letais intencionais em Pernambuco. Dados consolidados. Recuperado de http://www.portaisgoverno.pe.gov.br/web/sds/lista-vitimas-cvli

Prudente, N. M. (2010). Para uma cultura de paz: direitos humanos e justiça restaurativa. In M. Pelizzoli (Org.), Cultura de paz: restauração e direitos (pp. 81-102). Recife, PE: EDUFPE.

Ramalho, Z. (2000). O meu país. Álbum Nação Nordestina. 1 disco laser (56 min.), 4,8 pol. São Paulo: BMG.

Rodrigues, L. (2014). Alternativa: Justiça Restaurativa contra encarceramento em massa. Revista Caros Amigos, 18(69), 27-30.

Souza, E. L. A., \& Züge, M. B. A. (2011). Direito à palavra: interrogações acerca da proposta da justiça restaurativa. Psicologia: Ciência e Profissão, 31(4), 826-839. https://doi.org/10.1590/S1414-98932011000400012

United Nations Office on Drugsand Crime - UNODC. (2013). Global study on homicide 2013: trends, contexts, data. Viena: o autor. Recuperado de http://www.unodc.org/gsh

Waiselfisz, J. J. (2013). Mapa da violência 2013: homicídios e juventude no Brasil. Brasília, DF: Centro Brasileiro de Estudos Latino-Americano.

Waiselfisz, J. J. (2014). Mapa da violência 2014: os jovens do Brasil. Brasília, DF: Centro Brasileiro de Estudos Latino-Americano.

Waiselfisz, J. J. (2015). Mapa da violência 2015: adolescentes de 16 e 17 anos do Brasil: mortes matadas por armas de fogo. Brasília, DF: Centro Brasileiro de Estudos Latino-Americano.

Zehr, H. (2012). Justiça restaurativa: teoria e prática. (T. V. Acker, Trans.; Série Da reflexão à ação). São Paulo, SP: Palas Athena.

Zehr, H. (1990). Trocando as lentes: um novo foco para o crime e a justiça. Porto Alegre, RS: Herald.

Nemésio Dario Vieira de Almeida

Doutor em Psicologia pela Universidade Federal de Pernambuco (UFPE). Mestre em Psicologia pela Pontifícia Universidade Católica do Rio Grande do Sul (PUC-RS). Psicólogo Jurídico da Vara da Infância e Juventude do Tribunal de Justiça de Pernambuco. Especialista em Psicologia Jurídica pelo Conselho Federal de Psicologia. Pesquisador do Núcleo de Pesquisa em Epistemologia Experimental e Cultural da UFPE, Recife, PE, Brasil. E-mail: nemesiodario@hotmail.com

Endereço para envio de correspondência:

Rua Adonis de Souza, 26, Pina. CEP: 51110-210.

Recife-PE, Brasil

Recebido:22/08/2016

Data de reformulação: 19/05/2017

Aprovado: 06/06/2017

Como citar: Almeida, N. D. V. (2017). Análise dos homicídios em Pernambuco e as contribuições da justiça restaurativa. Psicologia: Ciência e Profissão, 37(3), 565-578. https://doi.org/10.1590/1982-3703003172016

How to cite: Almeida, N. D. V. (2017). Analysis of Homicides in Pernambuco and the contributions of restorative Justice. Psicologia: Ciência e Profissão, 37(3), 565-578. https://doi.org/10.1590/1982-3703003172016

Cómo citar: Almeida, N. D. V. (2017). Análisis de los homicidios en Pernambuco y las contribuciones de la justicia restaurativa. Psicologia: Ciência e Profissão, 37(3), 565-578. https://doi.org/10.1590/1982-3703003172016 


\section{ERRATA}

Na edição 37.3, no artigo "Análise dos Homicídios em Pernambuco e as Contribuições da Justiça Restaurativa”, nas página 578, onde se lê "Doutor em Psicologia pela Pontifícia Universidade Católica do Rio Grande do Sul (PUC-RS), Mestre em Psicologia pela Universidade Federal de Pernambuco (UFPE).", correto é: “Doutor em Psicologia pela Universidade Federal de Pernambuco (UFPE). Mestre em Psicologia pela Pontifícia Universidade Católica do Rio Grande do Sul (PUC-RS). Psicólogo Jurídico da Vara da Infância e Juventude do Tribunal de Justiça de Pernambuco. Especialista em Psicologia Jurídica pelo Conselho Federal de Psicologia. Pesquisador do Núcleo de Pesquisa em Epistemologia Experimental e Cultural da UFPE, Recife, PE, Brasil". 